\title{
BMJ Open Egocentric social network characteristics and cardiovascular risk among patients with hypertension or diabetes in western Kenya: a cross-sectional analysis from the BIGPIC trial
}

To cite: Ruchman SG, Delong AK, Kamano JH, et al. Egocentric social network characteristics and cardiovascular risk among patients with hypertension or diabetes in western Kenya: a cross-sectional analysis from the BIGPIC trial. BMJ Open 2021;11:e049610. doi:10.1136/ bmjopen-2021-049610

- Prepublication history and additional supplemental material for this paper are available online. To view these files, please visit the journal online. (http://dx.doi.org/10.1136/ bmjopen-2021-049610).

Received 28 January 2021 Accepted 11 August 2021

Check for updates

(c) Author(s) (or their employer(s)) 2021. Re-use permitted under CC BY-NC. No commercial re-use. See rights and permissions. Published by BMJ.

For numbered affiliations see end of article.

Correspondence to Dr Rajesh Vedanthan; rajesh.vedanthan@nyulangone. org and

Dr Samuel G Ruchman; samuel.ruchman@cuanschutz. edu

\section{ABSTRACT}

Objectives Management of cardiovascular disease (CVD) is an urgent challenge in low-income and middle-income countries, and interventions may require appraisal of patients' social networks to guide implementation. The purpose of this study is to determine whether egocentric social network characteristics (SNCs) of patients with chronic disease in western Kenya are associated with overall CVD risk and individual CVD risk factors.

Design Cross-sectional analysis of enrollment data (2017-2018) from the Bridging Income Generation with GrouP Integrated Care trial. Non-overlapping trustonly, health advice-only and multiplex (trust and health advice) egocentric social networks were elicited for each participant, and SNCs representing social cohesion were calculated.

Setting 24 communities across four counties in western Kenya.

Participants Participants ( $\mathrm{n}=2890$ ) were $\geq 35$ years old with diabetes (fasting glucose $\geq 7 \mathrm{mmol} / \mathrm{L}$ ) or hypertension. Primary and secondary outcomes We hypothesised that SNCs would be associated with CVD risk status (QRISK3 score). Secondary outcomes were individual CVD risk factors.

Results Among the 2890 participants, 2020 (70\%) were women, and mean (SD) age was 60.7 (12.1) years. Forty-four per cent of participants had elevated QRISK3 score $(\geq 10 \%)$. No relationship was observed between QRISK3 level and SNCs. In unadjusted comparisons, participants with any individuals in their trust network were more likely to report a good than a poor diet $(41 \%$ vs $21 \%$ ). SNCs for the trust and multiplex networks accounted for a substantial fraction of variation in measures of dietary quality and physical activity (statistically significant via likelihood ratio test, adjusted for false discovery rate).

Conclusion SNCs indicative of social cohesion appear to be associated with individual behavioural CVD risk factors, although not with overall CVD risk score. Understanding how SNCs of patients with chronic diseases relate to

\section{STRENGTHS AND LIMITATIONS OF THIS STUDY \\ $\Rightarrow$ The social network characteristics (SNCs) of pa- tients with chronic diseases in Africa are understud- ied but describing the relationship between SNCs and modifiable cardiovascular disease (CVD) risk factors could help inform interventions. \\ $\Rightarrow$ With a large sample of clinical and lifestyle survey data, we were able to investigate the relationships between SNCs and overall CVD risk (QRISK3 score) as well as with numerous individual CVD risk factors. \\ $\Rightarrow$ We used Efron's local false discovery rate method to adjust for multiple comparisons. \\ $\Rightarrow$ Although there is no prospectively validated cardio- vascular risk assessment measure for this popu- lation at the current time, QRISK3 was chosen for this study because it has been used in other black African populations. \\ $\Rightarrow$ We present the results of a cross-sectional analysis and so we are not able to comment on causality.}

modifiable CVD risk factors could help inform networkbased interventions.

Trial registration number ClinicalTrials.gov identifier: NCT02501746; https://clinicaltrials.gov/ct2/show/ NCT02501746.

\section{INTRODUCTION}

Management of cardiovascular disease (CVD) is an urgent challenge, especially in low and middle-income countries (LMICs), where more than $70 \%-80 \%$ of premature deaths from CVD occur. ${ }^{2}$ Appraisal of patients' social networks might help guide delivery of tailored, effective care for individuals with CVD and CVD risk factors. In fact, social network analysis has been applied to understand the spread and modification of 
behaviours and risk factors for CVD, such as obesity, diet and tobacco use. ${ }^{3-7}$

Social network characteristics (SNCs) may influence health outcomes by exposing individuals to resources, information and behaviours in ways that are associated with people who are important social ties (eg, spouses pressuring smokers into cessation) or exhibit some form of social capital (eg, the propensity of high school students to smoke increasing with the popularity of other smokers) ${ }^{58-10}$ Some network scholars theorise that social connections to individuals who exhibit positive health behaviours may reinforce personal identity and sense of belonging, encouraging the positive health behaviour. ${ }^{11}$ This theory has been tested empirically when the adoption of a health behaviour was improved by creating networks in which individuals received reinforcement from more people in the network. ${ }^{12}$ The type of relationship (including the sex of both individuals in a friendship) has also been observed to have implications for the diffusion of health characteristics such as obesity, possibly by altering individuals' norms. ${ }^{3}$ In health and other sociological contexts, studies have shown that in times of specific need, individuals may rely on members of their networks with whom they are less close but who have access to specific resources or information, reiterating the idea that health outcomes could be related to SNCs by mediating the diffusion of tangible and intangible resources. ${ }^{13}{ }^{14}$ SNCs relationship with health outcomes is likely multifactorial, related to the number and type of connections an individual has as well as the context in which an individual needs or is exposed to resources, information and behaviours.

Egocentric networks are personal social networks constituted of the individuals ('alters') known by one person ('ego'). ${ }^{15}$ Egocentric SNCs that are markers of social cohesion have been associated with health outcomes. ${ }^{16}$ Recent studies have shown that egocentric SNCs, such as network size, may be relevant to CVD through their beneficial relationship with physical activity. ${ }^{17} 18$ Smaller network sizes have also been associated with increased risk of stroke. ${ }^{19}$ Studies of social networks in LMICs have examined diverse health topics, including contraception use, infant mortality, mercury consumption and diarrheal disease. ${ }^{20-25}$ However, to our knowledge, there have been few studies of SNCs among patients with chronic diseases in Africa. ${ }^{24}$

The purpose of this study, therefore, is to explore the relationship between CVD risk and egocentric SNCs of patients with diabetes and/or hypertension in Kenya. We hypothesised that SNCs indicative of stronger social cohesion (eg, larger network sizes, more social activities shared with alters, more frequent contact with alters) would be associated with lower overall CVD risk and modifiable CVD risk factors. Because it has been observed empirically that 'functionally specific' social networks (ie, networks composed of people with whom an individual discusses health or health problems) may be most relevant to health outcomes, ${ }^{132627}$ we also hypothesised that
SNCs of health advice-only networks would be more strongly associated with health outcomes than SNCs of trust-only networks.

\section{METHODS}

\section{Setting and participants}

We analysed baseline data $(n=2890)$ from participants enrolled in the Bridging Income Generation with GrouP Integrated Care (BIGPIC) study, a clusterrandomised trial designed to investigate whether group medical visits, in combination with or independent of a microfinance intervention, can reduce the risk of CVD among individuals with diabetes and/or hypertension in western Kenya. Inclusion criteria for the BIGPIC study were adults 35 years or older in the Academic Model Providing Access to Healthcare Partnership's chronic disease management programme with diabetes (fasting glucose $\geq 7 \mathrm{mmol} / \mathrm{L}$ ), impaired fasting glucose (fasting glucose $5.6-6.9 \mathrm{mmol} / \mathrm{L})$ or increased risk of developing diabetes (Leicester Risk Assessment score $\geq 7$ ). ${ }^{28} 29$ All participants in both the BIGPIC study and in the analysis, we present here of BIGPIC participants' SNCs had either diabetes or hypertension (systolic blood pressure (SBP) $\geq 140 \mathrm{~mm} \mathrm{Hg}$ or diastolic blood pressure $\geq 90 \mathrm{~mm} \mathrm{Hg}$ ). Full details of the trial methods and procedures have been previously described. ${ }^{29} 30$

\section{Patient and public involvement}

No patients or members of the public were involved in the design, analysis or reporting of this study.

\section{Egocentric SNCs}

To generate data on egocentric social networks, participants were asked to name up to five individuals with whom they discuss 'important matters' and up to five individuals with whom they discuss 'health matters' and to provide information about their relationships with those individuals. ${ }^{22-24} 26$ 31-36 Asking study participants explicitly about 'health matters' to generate networks in which the members may be most relevant to health outcomes is an approach that has been deployed across several contexts, including to study the relationship between CVD risk factors and SNCs in a cohort in the Caribbean. ${ }^{18}$ 26 The social network survey was pilot tested to ensure comprehension and is similar to social network instruments that have been used globally. ${ }^{18} 24$ We asked each participant to characterise the nature of each network connection and used this information to identify up to three non-overlapping egocentric networks depending on the matters she or he discusses with their respective alters: (1) trust-only network, exclusively for 'important matters,' (2) advice-only network, exclusively for 'health matters' and (3) multiplex network, for both 'important' and 'health matters.' For example, a participant who named three people total-one in response to both the 'important' and 'health matters' questions and two for 'health matters' only-has one multiplex, 


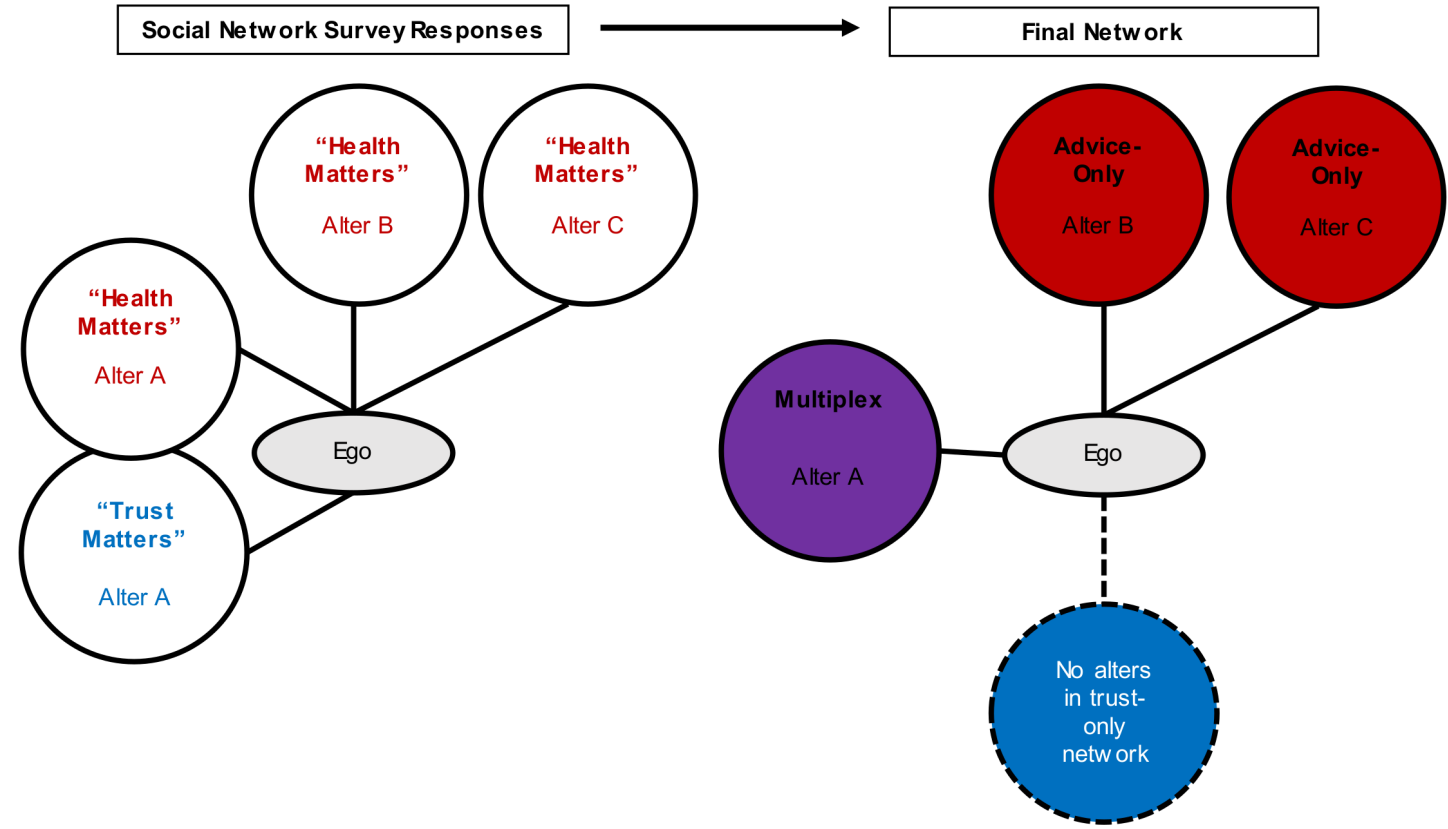

Figure 1 Example of an egocentric network. This example participant responds to the social network survey saying she discusses 'important matters' with alter A and 'health matters with alters A, B and C. Because the participant discusses both 'important' and 'health matters' with alter A, alter A is in the multiplex (trust and advice) network, leaving just alters B and C in the advice-only network and no alters in the trust-only network.

two advice-only, and zero trust-only alters (figure 1). Participants who did not name alters for any network are labelled 'isolates'. 815

For each of the three networks and for each individual, we calculated five egocentric SNCs that represent social cohesion by representing the size of the network, strength of relationships and sex composition ${ }^{815}$ : (1) degree: the total number of alters in the network, (2) mean duration of relationship: the average duration of the ego's relationship with alters, in years, (3) mean frequency of contact: how often, on average, the ego speaks with alters, on a five-item scale (options: never $=1$, at least every couple of months $=2$, at least monthly=3, at least weekly=4, at least daily=5), (4) mean number of shared activities: the average count of the number of organisations in which the ego participates with her or his alters (options: church, work, club, group medical visit, microfinance group, other (specify), none), (5) proportion male: the proportion of alters in the network who are men. In addition, sex homophily (the proportion of alters in the network who are the same sex as the ego) and proportion kin (the proportion of alters in the network who are immediate or extended family members (eg, cousins) of the ego) were calculated for each network for descriptive purposes. ${ }^{18}$

\section{Clinical and socioeconomic characteristics}

Clinical measurements included blood pressure, blood glucose, lipid panel and body mass index (BMI). Lipids and glucose were measured using the Cardiocheck PA and Freestyle Optimum point-of-care systems, respectively. Each participant had either a fasting or random lipid panel, depending on fasting status. Abnormal lipids were defined as: total cholesterol $\geq 5.17 \mathrm{mmol} / \mathrm{L}$, high density lipoprotein $(\mathrm{HDL}) \leq 1.03 \mathrm{mmol} / \mathrm{L}$, low density lipoprotein $(\mathrm{LDL}) \geq 4.14 \mathrm{mmol} / \mathrm{L}$, triglycerides $\geq 1.70 \mathrm{mmol} / \mathrm{L}$. ${ }^{37}$ A questionnaire at baseline elicited information on medical history and relevant health behaviours (eg, diet, physical activity, alcohol and tobacco use), tailored to local context. ${ }^{30}$ Participants were also asked about socioeconomic characteristics and non-monetary indicators of wealth (eg, ownership of land, livestock and household construction and items). Summative clinical and wealth measures were calculated, including QRISK3 score, which measures 10 -year risk of heart attack or stroke, ${ }^{39}$ and the validated asset-based International Wealth Index (IWI). ${ }^{40}$

The primary outcome of interest is QRISK3 score. Secondary outcomes are individual CVD risk factors $^{41}$ : diabetes status (self-reported diagnosis, or having fasting glucose $\geq 7 \mathrm{mmol} / \mathrm{L}$ or having random glucose $\geq 11.1 \mathrm{mmol} / \mathrm{L}$ ), SBP, total cholesterol, LDL cholesterol, BMI, current tobacco use (of any form), diet number of servings of fruit or vegetables per day), physical activity (moderate-equivalent minutes per week).

\section{Statistical analysis}

Table 1 provides an overall summary of the different statistical analyses performed. Demographic characteristics, primary and secondary outcomes, additional clinical measures and SNCs were summarised and stratified by sex to identify any sex-related differences in health, wealth and social networks within the population. ${ }^{42-45}$

Bivariate summaries of SNCs in each network by categorised CVD risk factor were produced. For this, each risk factor was dichotomised using cut-off points that indicate 
Table 1 Summary of statistical analyses performed

\begin{tabular}{lllll}
\hline Analysis & Purpose & Models & Stratification or adjustment & Location \\
\hline $\begin{array}{l}\text { Descriptive } \\
\text { statistics }\end{array}$ & $\begin{array}{l}\text { Summarise study population's } \\
\text { clinical and socioeconomic } \\
\text { status, and demographic and } \\
\text { social network characteristics }\end{array}$ & n/a & Stratified by sex & Tables 2 and 3, online \\
supplemental table S2
\end{tabular}

CVD, cardiovascular disease; LDL, low density lipoprotein; SNC, social network characteristic.

elevated risk status: QRISK3 $\geq 10 \%,{ }^{39} \mathrm{SBP} \geq 180 \mathrm{~mm} \mathrm{Hg}$ (as an additional cut-off of elevated cardiovascular risk, in line with the definition of hypertensive urgency, because most participants (approximately 93\%) already met standard Kenyan criteria for hypertension), ${ }^{29} 47$ total cholesterol $\geq 5.17 \mathrm{mmol} / \mathrm{L}$, LDL cholesterol $\geq 4.14 \mathrm{mmol} / \mathrm{L},{ }^{37}$ BMI $\geq 25$, intake of fruits or vegetables per day $<5$ servings and physical activity per week $<150$ moderate-equivalent minutes. ${ }^{1}$ Isolates across the network types $(\mathrm{n}=122)$ were excluded from these summaries of SNCs because SNCs cannot be calculated for participants with no alters. Similarly, participants with network-specific degree of zero were excluded from the summaries of respective subgroups (trust-only, n=2094; advice-only, $\mathrm{n}=1944$; multiplex, $\mathrm{n}=611$ ).

To characterise the effect of each SNC on each CVD risk outcome, we used multivariable regressions that included all five SNCs for each of the three networks (trust-only, advice-only and multiplex) as independent variables. Because social isolation may impact CVD risk, ${ }^{48} 49$ an additional categorical indicator variable for having no alters in a particular network was added, and covariates for other SNCs were set to zero for participants with no alters in that network. Durations of relationships, prior to taking their mean, and degree were $\log (\mathrm{x}+1)$ transformed to account for skewness. All models were additionally adjusted for facility, participant age, sex and self-reported health (0-100) from a Visual Analog Scale. ${ }^{50-54}$ We examined the impact of network-specific SNCs on five continuous (SBP, and log-transformed QRISK, total cholesterol, LDL and BMI) and four categorical (diet, physical activity, tobacco use and diabetes status) outcomes in total, using linear and logistic regressions, respectively. The estimated parameters and 95\% CI show the independent effect, in terms of magnitude, directionality and variability, of each SNC on each outcome.

Finally, we use the same multivariable modelling framework to test the effect of each type of network on each CVD risk factor. Likelihood ratio tests of nested models were used to assess whether SNCs from a specific network were a significant source of variation for each of the primary and secondary outcomes. For each of the three networks, we captured the $p$ values from four comparisons of models with versus without the network's SNCs. Online supplemental table S1 describes the nested models used in each of the 12 comparisons. For example, to quantify the effect of the health-advice network relative to trust and multiplex networks (see column 1 in online supplemental table S1), we make the following comparisons: (1) healthadvice versus none, (2) health-advice plus trust versus trust only, (3) health-advice plus multiplex versus multiplex only and (4) health-advice plus trust plus multiplex versus trust plus multiplex. Each of these nested model comparisons isolates the effect of health-advice networks relative to the others. To adjust for multiple comparisons, we used Efron's local false discovery rate method, with the false discovery rate set to $0.05 .{ }^{55}$

\section{RESULTS}

\section{Participant characteristics}

Demographic and socioeconomic characteristics

Participants had a mean age of 60.7 years (table 2). Nearly $90 \%$ of the participant population reported either no formal employment or monthly earnings of less than 
Table 2 Demographic and socioeconomic characteristics, by sex

\begin{tabular}{|c|c|c|c|}
\hline Variable & Total (\%) or mean (SD) & Female & Male \\
\hline Total & 2890 & 2020 & 870 \\
\hline \multicolumn{4}{|l|}{ Age (years) } \\
\hline Mean (SD) & $60.7(12.1)$ & $59.2(11.8)$ & $64.2(12.2)$ \\
\hline $35-44$ & $279(10)$ & $221(11)$ & $58(7)$ \\
\hline $45-54$ & $634(22)$ & $509(25)$ & $125(14)$ \\
\hline $55-64$ & $828(29)$ & $586(29)$ & $242(28)$ \\
\hline $65-74$ & $760(26)$ & $499(25)$ & $261(30)$ \\
\hline$\geq 75$ & $389(13)$ & $205(10)$ & $184(21)$ \\
\hline \multicolumn{4}{|l|}{ International Wealth Index } \\
\hline Mean (SD) & $29.4(17.6)$ & $28.2(17.3)$ & $32.2(18.0)$ \\
\hline Missing & 2 & 1 & 1 \\
\hline \multicolumn{4}{|l|}{ Monthly earnings (KES) } \\
\hline No job & $1838(64)$ & $1363(67)$ & $475(55)$ \\
\hline$<1000$ & $315(11)$ & $252(12)$ & $63(7)$ \\
\hline 1000-2999 & $252(9)$ & $163(8)$ & $89(10)$ \\
\hline 3000-4999 & $179(6)$ & $98(5)$ & $81(9)$ \\
\hline 5000-9999 & $138(5)$ & $61(3)$ & 77 (9) \\
\hline$\geq 10000$ & $134(5)$ & $60(3)$ & $74(9)$ \\
\hline Refused & $3(0)$ & $3(0)$ & $0(0)$ \\
\hline Unknown & $27(1)$ & $18(1)$ & $9(1)$ \\
\hline Missing & $4(0)$ & $2(0)$ & $2(0)$ \\
\hline \multicolumn{4}{|l|}{ Reason for not working (if no job) } \\
\hline Retired & $824(45)$ & $462(34)$ & $362(76)$ \\
\hline Taking care of home or family & $610(33)$ & $590(43)$ & $20(4)$ \\
\hline Could not find work & $222(12)$ & $174(13)$ & $48(10)$ \\
\hline Illness or disability & $138(8)$ & $104(8)$ & $34(7)$ \\
\hline Temporary layoff & $3(0)$ & $1(0)$ & $2(0)$ \\
\hline Wanted some time off & $4(0)$ & $3(0)$ & $1(0)$ \\
\hline Other & $36(2)$ & $28(2)$ & $8(2)$ \\
\hline Missing & $1(0)$ & $1(0)$ & $0(0)$ \\
\hline \multicolumn{4}{|l|}{ Livestock owned } \\
\hline No & $1010(35)$ & $777(38)$ & $233(27)$ \\
\hline Yes & $1873(65)$ & $1239(61)$ & $634(73)$ \\
\hline Missing & $7(0)$ & $4(0)$ & $3(0)$ \\
\hline \multicolumn{4}{|l|}{ Acres of land owned } \\
\hline Mean (SD) & $4.0(6.2)$ & $3.6(5.8)$ & $4.8(6.9)$ \\
\hline Missing & 13 & 10 & 3 \\
\hline \multicolumn{4}{|l|}{ Education of head of household } \\
\hline Primary & $1784(62)$ & $1289(64)$ & $495(57)$ \\
\hline Secondary & $754(26)$ & $476(24)$ & $278(32)$ \\
\hline Post-grad & $5(0)$ & $1(0)$ & $4(0)$ \\
\hline University & $145(5)$ & $91(5)$ & $54(6)$ \\
\hline Unknown & $185(6)$ & $152(8)$ & $33(4)$ \\
\hline Refused & $15(1)$ & $10(0)$ & $5(1)$ \\
\hline Missing & $1(0)$ & $1(0)$ & $0(0)$ \\
\hline
\end{tabular}


Table 2 Continued

\begin{tabular}{lcrl}
\hline Variable & Total (\%) or mean (SD) & Female & Male \\
\hline Self-reported health (0-100) & & & \\
\hline$<50$ & $393(14)$ & $287(14)$ & $106(12)$ \\
\hline $50-74$ & $2144(74)$ & $1532(76)$ & $612(70)$ \\
\hline 75 & $350(12)$ & $199(10)$ & $151(17)$ \\
\hline Missing & $3(0)$ & & $1(0)$ \\
\hline KES, Kenyan Shillings. & & & \\
\hline
\end{tabular}

5000 Kenyan Shillings (KES) (approximately US\$50). A greater share of women than men reported no formal employment $(67 \%$ vs $55 \%)$, and women who were employed earned lower wages than men. Among those with formal employment, nearly 30\% reported earning less than 1000 KES (roughly US\$10) per month, again more predominant among women. Women were less wealthy than men (mean IWI 28.2 vs 32.2 ), and a smaller portion of women-owned livestock ( $61 \%$ vs $73 \%)$.

\section{Cardiovascular risk factors}

Forty-four per cent of women and men had a QRISK3 score greater than or equal to $10 \%$ (online supplemental table S2), and $14 \%$ of participants had QRISK3 score greater than or equal to $20 \%$ ( $16 \%$ of men vs $14 \%$ of women). Participants had a mean SBP of $157.5 \mathrm{~mm} \mathrm{Hg}$ and $21 \%$ had diabetes. Women were more likely to be overweight or obese than men (50\% vs $33 \%)$. Eighty-five per cent of participants reported eating fewer than five servings of fruit and vegetables per day, and $40 \%$ reported fewer than 150 moderate-equivalent minutes of exercise per week, similar by sex. Sixteen per cent of participants with a fasting test and $14 \%$ of participants with a random test had total cholesterol greater than or equal to $5.17 \mathrm{mmol} / \mathrm{L}$. Abnormally low HDL (38\% fasting test, $36 \%$ random test) and elevated triglycerides (45\% fasting test, $35 \%$ random test) were more common patterns of dyslipidaemia than elevated LDL.

\section{Egocentric SNCs}

Overall, 122 participants-4\% of women and $4 \%$ of men-were isolates; the other $96 \%$ of participants reported at least one alter in at least one of the mutually exclusive networks. Seventy-six per cent of participants had no trust-only alters and $70 \%$ had no advice-only alters, but only $22 \%$ of participants had no multiplex alters (table 3). Most participants had zero or one alter in any given network. Most participants spoke to alters daily, on average, but the majority shared no social activities with their alters. Multiplex networks showed a high degree of sex heterophily, with $67 \%$ of multiplex networks entirely comprising alters that were the opposite sex of the participants. Alters were also likely to be family members and known for more than 20 years.

\section{SNCs' association with CVD risk}

The distributions of SNCs, including network degree (figure 2A), within each network were similar among individuals with different QRISK3 levels (table 4). The summaries did not show large differences between No substantive differences were observed between SNCs and diabetes status or elevated SBP (online supplemental tables S3 and S4). Participants with any trust network alters were more likely to report a good than a poor diet (41\% vs 21\%) (figure 2B and online supplemental table S5). Similarly, participants with any trust network alters were more likely to report sufficient than insufficient levels of physical activity (29\% vs 16\%) (figure 2C and online supplemental table $\mathrm{S} 6$ ). No relationships were observed between SNCs and total cholesterol, LDL, BMI or tobacco use (results not shown).

Multivariable models of log-transformed QRISK3 did not show any association between SNCs and GVD risk (online supplemental table S7). Number of and mean frequency of contact with trust network alters had positive associations with good diet; number of advice and multiplex network alters had positive associations with sufficient physical activity. Number of advice network alters and mean number of activities shared with them had inverse relationships with SBP, while these same SNCs in the multiplex network had a positive association with SBP. Results for diabetes status, total cholesterol, LDL, BMI and current tobacco use are also shown in online supplemental table S7.

The results of the likelihood ratio tests indicated that the SNCs for the trust and multiplex networks explained a significant amount of variation in diet and physical activity, even after adjusting for multiple comparisons (figure 3 and online supplemental table S8). We did not find evidence that characteristics of any of the networks explained substantial variation in SBP, diabetes status, total cholesterol, LDL, current tobacco use or BMI.

\section{DISCUSSION}

This cross-sectional study examined the relationship of egocentric SNCs with overall CVD risk and individual CVD risk factors, in a population of individuals with diabetes or hypertension in western Kenya. The study population was materially poor and reported small egocentric social 
Table 3 Summary of egocentric social network characteristics, by sex and network

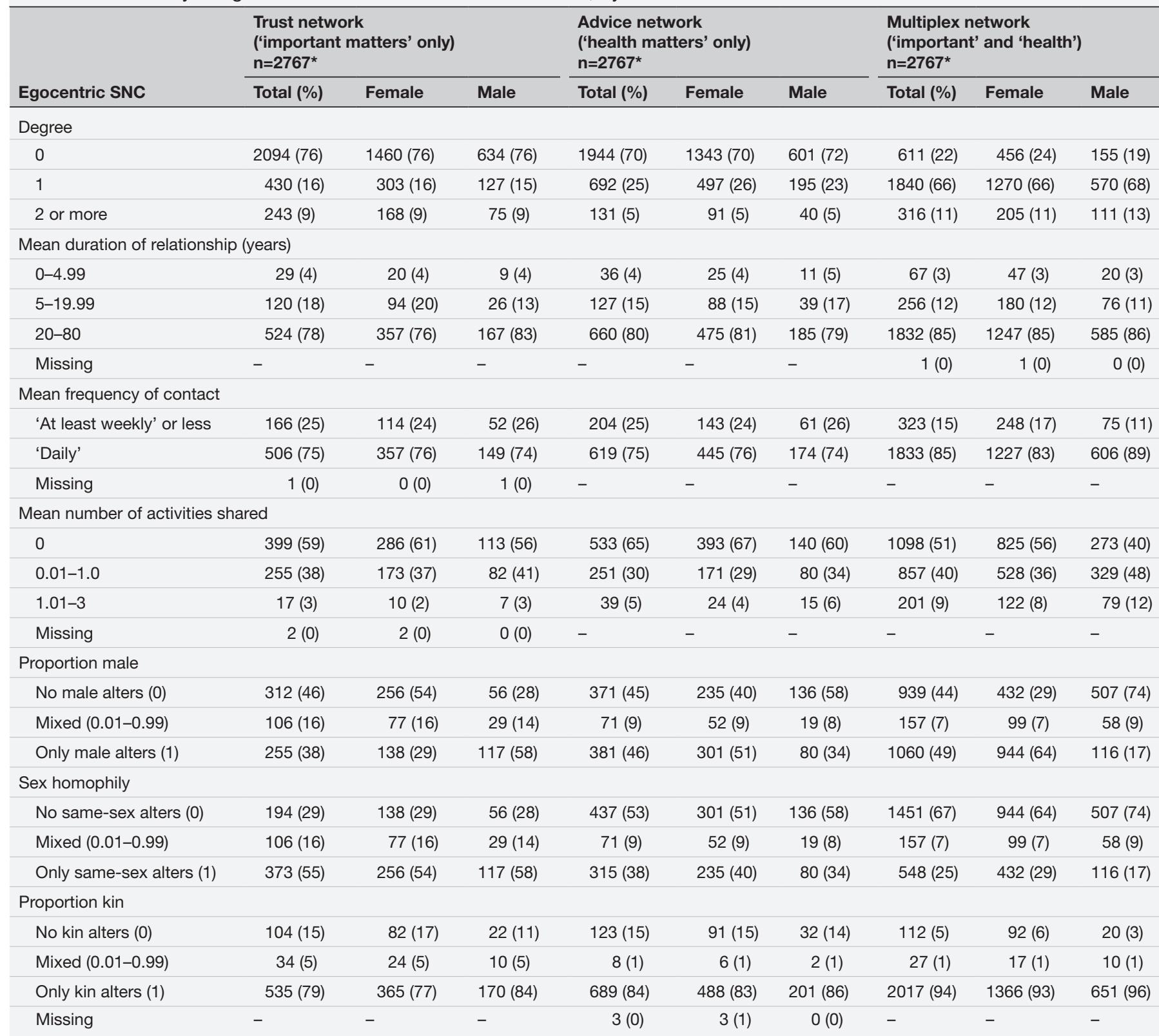

*Isolates (122 participants) and 1 participant with missing data were excluded from the analysis. For each network, SNCs other than degree are only reported for participants who had at least one alter in that network.

SNC, social network characteristic.

networks. More than $40 \%$ of the study population had elevated CVD risk. SNCs were not associated with QRISK3 score in our analysis. However, SNCs representing social cohesion were associated with better diet and physical activity. This study expands research regarding egocentric social networks and CVD risk in an under-studied African context.

This cohort of Kenyan patients with chronic disease included a sizeable proportion with elevated CVD risk. Relatively few participants had elevated LDL cholesterol, but a large number having elevated triglycerides, a notable pattern of dyslipidaemia consistent with that previously reported in a cohort of patients at a Kenyan clinic with type 2 diabetes. ${ }^{56}$ Insufficient intake of fruits and vegetables, a leading preventable dietary risk factor for noncommunicable disease-related morbidity and mortality worldwide ${ }^{57}$ was a highly prevalent CVD risk factor in our study population, consistent with findings of a nationally representative 2015 Kenyan survey. ${ }^{58}$ Self-reported tobacco and alcohol use were uncommon, in contrast to a nationally representative survey in which $13 \%$ reported some form of tobacco use and 19\% reported alcohol consumption. ${ }^{5} 59$

The BIGPIC study population was rurally based and materially poor. Nearly all participants reported no formal employment or daily earnings less than US\$1.25/day, 
(A)

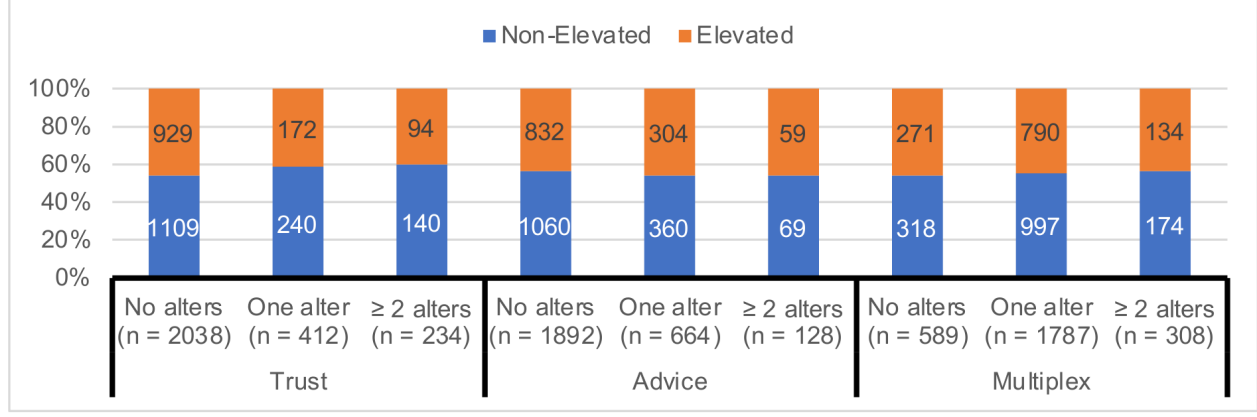

(B)

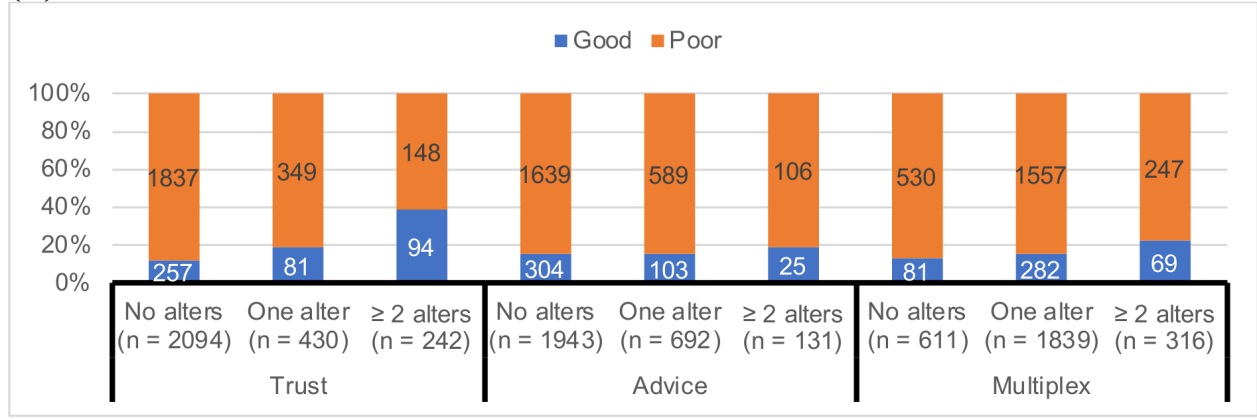

(C)

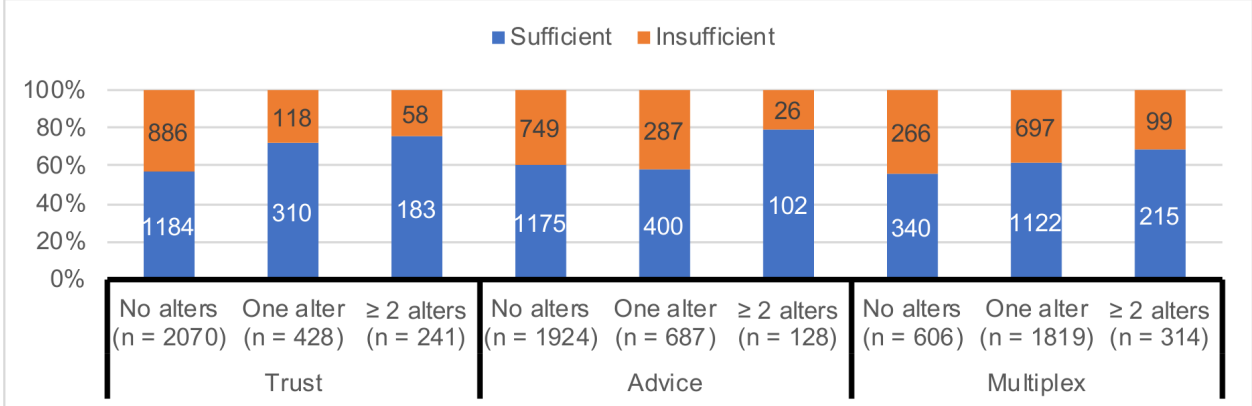

Figure 2 Distribution of CVD risk status and behavioural CVD risk factors (diet and physical activity) by network and degree. Bars illustrate the distribution of CVD risk status and behavioural risk factors for trust, advice and multiplex networks by network degree (no alters, one alter or two or more alters). (A) CVD risk status (elevated CVD: QRISK $\geq 10 \%$ ), by network and degree. (B) Diet, by network and degree. (C) Physical activity, by network and degree. CVD, cardiovascular disease.

and the cohort's mean IWI also correlated with a Poverty Headcount Ratio of less than US $\$ 1.25 /$ day. ${ }^{40}$ The severe financial poverty of our sample underscores the need to improve access to healthcare resources and design models of care delivery and healthcare financing that incorporate social determinants of health into chronic disease management.

Although we hypothesised that we would observe a relationship between egocentric SNCs and overall CVD risk as quantified by QRISK3, no such association was evident. However, multivariable models suggested a possible inverse relationship between some advicenetwork SNCs and highly elevated SBP, adding to the conflicting evidence previously described in the literature. One methodologically similar study found no relationship between health-advice SNCs and hypertension in Caribbean population, after adjusting for demographic variables. $^{18}$ Studies in US, English and Spanish populations have suggested protective relationships between egocentric SNCs and 10-year mortality from some forms of $\mathrm{CVD}^{60-62}$ but found mixed evidence for relationships with hypertension outcomes. ${ }^{606364}$

We observed associations between egocentric SNCs and modifiable behavioural CVD risk factors, such as diet and physical activity. This pattern is consistent with findings from studies of egocentric social networks in other geographies that have suggested positive relationships between larger, more cohesive networks with more favourable physical activity and/or diet. ${ }^{171865-67}$ One possible explanation for the apparent relationship between SNCs and physical activity is that individuals with larger egocentric networks may have more alters who are physically active, which could encourage the positive health behaviour. ${ }^{1168}$ Social network scholars have also previously hypothesised that health outcomes may be related to SNCs through diffusion of information, resources and norms for behaviours and attitudes. ${ }^{8}$ Given that this study was cross-sectional and, therefore, we cannot comment on causality, we resist speculating on the mechanism of the relationships we observed. Identifying the mechanisms 
Table 4 Egocentric social network characteristics, by QRISK3 and network

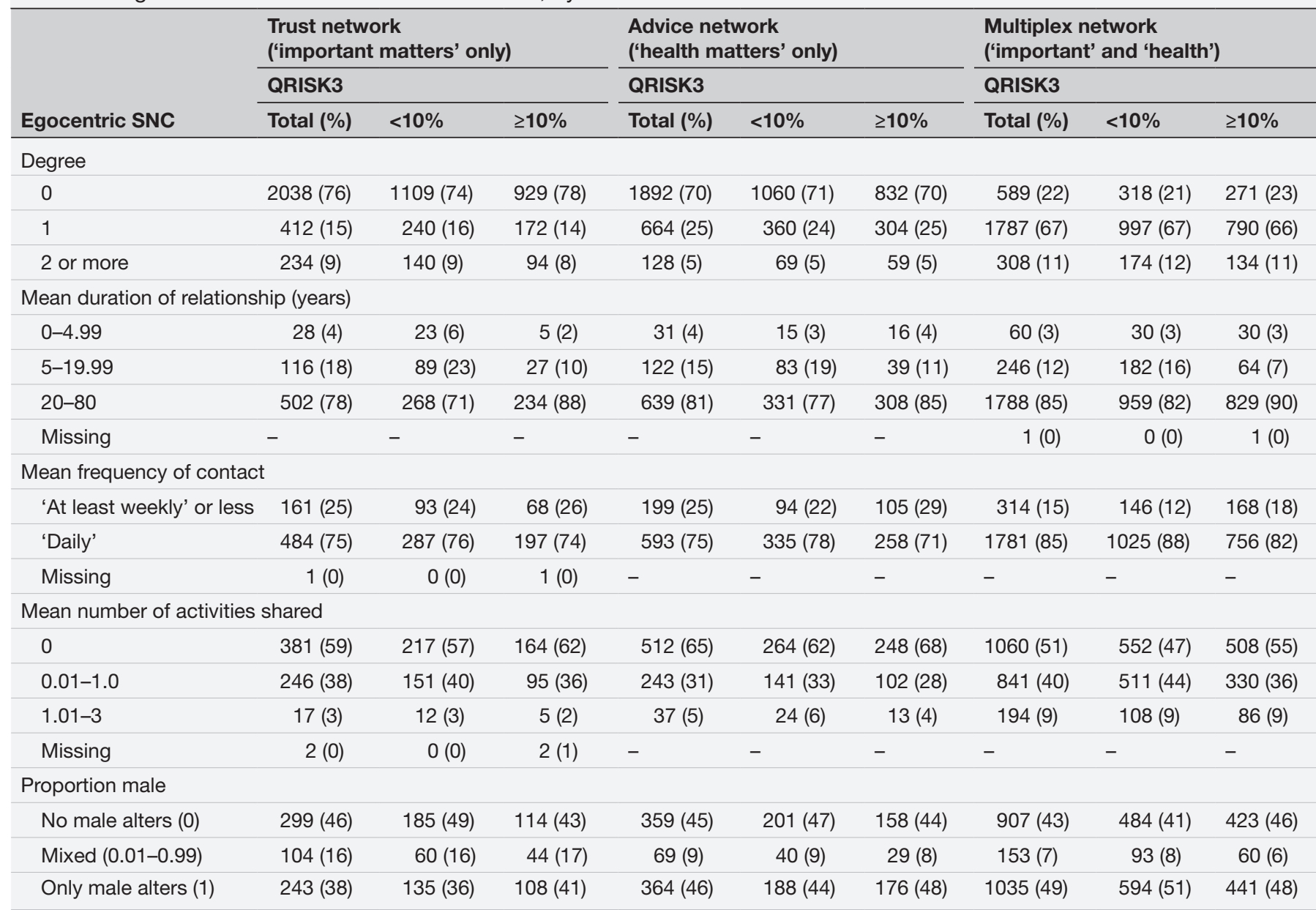

SNC, social network characteristic.

for any observed association between SNCs and modifiable behavioural CVD risk factors would require greater information about alters (eg, to control for homophily of health characteristics) as well as longitudinal data to observe changes to both networks and health over time, which may be possible in future publications leveraging data from the BIGPIC study.

We also initially hypothesised that the health-advice network SNCs would be more predictive of health outcomes than the more general trust network SNCs, based on previous studies of health-related egocentrical social networks and theory of social networks' functional specificity. ${ }^{13} 1826$ Counter to our hypothesis, an association between health-advice network SNCs and these behavioural risk factors was not evident. Multivariable models suggested an association between advice and multiplex network SNCs and SBP. There was also an overall trend across bivariate and multivariable models suggesting an association between trust and multiplex network SNCs and diet and physical activity. It is possible that, at baseline, patients in the BIGPIC cohort rely more on core discussion networks for health-related information and resources than on the targeted mobilisation of health network resources that has been described in other literature. ${ }^{1326}$ The underlying reasons for this greater reliance on core discussion networks could be due to structural barriers (eg, poor access to established health resources such as clinics or geographic distance from socially weaker ties) or cultural norms (eg, preferring to discuss health problems only with family members).

We observed a relationship between SNCs of multiplex networks and risk factors such as diet, physical activity and SBP. Because many participants had multiplex networks comprising only one alter, often kin and opposite sex, we speculate that these multiplex-network alters were spouses, though we did not specifically confirm this in the social network survey. This type of strong relationship with alters, such as a spousal relationship, could be more influential over behavioural changes. ${ }^{869}$

\section{Study limitations}

We acknowledge several limitations. First, because we present the results of a cross-sectional analysis, we are not able to comment on causality. Second, to preserve the brevity of the social network survey, questions eliciting real or perceived alter-alter relationships were not asked, so structural properties of egocentric networks could not be calculated. However, we have been able to evaluate 


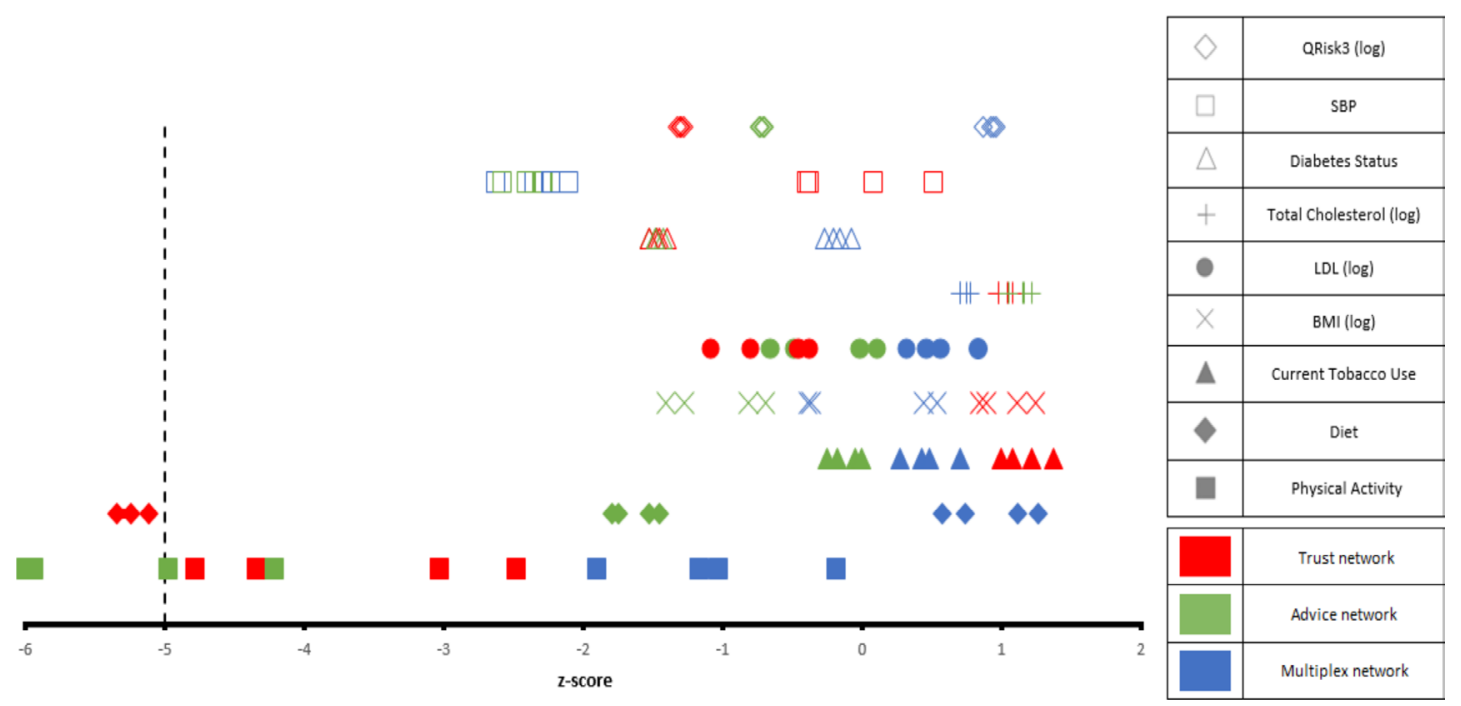

Figure 3 Results of likelihood ratio hypothesis tests for effect of social network characteristics on CVD risk factor outcomes, with multiple comparisons threshold indicated by vertical line. Owing to the compressed scale for $p$-values, we translated $p$ values to associated Z-scores to enable visible display of all models. Large negative Z-score deviations from zero correspond to smaller $\mathrm{p}$-values for each comparison (online supplemental table S1). For example, a Z-score of 0 corresponds to a p-value of 0.5 ; a Z-score of -1.96 corresponds to $p=0.025$. The dashed vertical line at $Z=-5$ is the threshold for statistical significance after adjusting for multiple comparisons; points to the left of that line represent statistically significant comparisons. Colour indicates type of social network SNCs added (red: trust network, blue: advice network, green: multiplex network). The plot shows that trust networks have an impact on diet, and that multiplex networks have an impact on physical activity. BMI, body mass index; CVD, cardiovascular disease; LDL, low density lipoprotein; SNC, social network characteristic.

alter-alter relationships during follow-up assessments of the BIGPIC trial participants, which we intend to evaluate and report in future publications. Third, the social network survey did not elicit information about advice specific to the health outcome of interest (CVD risk or individual risk factors), which might have influenced the findings. Fourth, that participants understood that alters could be identified by the research team might have influenced results of the social network survey. Fifth, while we recognise that social networks may operate differently by gender in certain populations, gender-stratified analyses were not prespecified in the original analysis plan. We feel that this important issue can be pursued subsequently in future analyses. Sixth, because the health-related behaviours (diet and physical activity) were self-reported, there remains a potential for recall bias. ${ }^{70}$ In addition, the point-of-care technology used to measure lipid levels may not be as accurate as serum lipid levels, especially in certain subpopulations; for example, LDL levels may have been underestimated..$^{71}$ Finally, although there is no prospectively validated cardiovascular risk assessment measure for this population at the current time, QRISK3 was chosen for this study because it has been used in other black African populations. ${ }^{39} 7273$ We recognise the shortcomings of this approach, ${ }^{74}$ but feel there is no currently available risk assessment tool that is superior. We anticipate that as increasing numbers of CVD cohort studies are completed in Africa in the future, more accurate and targeted risk calculators will become available, reducing this fundamental limitation.

\section{Conclusions}

The high and increasing burden of CVD in LMICs and the potential relationships between SNCs and CVD risk factors necessitate expanded research on social networks and CVD, especially in African populations. ${ }^{76-78}$ Our findings help to create a foundation for a more thorough understanding of SNCs of chronic disease patients in this context, which could help inform interventions for modifiable CVD risk factors. ${ }^{790}$ Ultimately, we hope that cardiovascular interventions can be implemented in ways that strengthen social networks, leveraging the relationship between SNCs and modifiable CVD risk factors to maximise health benefit, both in Kenya and worldwide.

\section{Author affiliations}

${ }^{1}$ Department of Medicine, Department of Pediatrics, University of Colorado, Aurora, Colorado, USA

${ }^{2}$ Department of Biostatistics, School of Public Health, Brown University, Providence, Rhode Island, USA

${ }^{3}$ Department of Medicine, Moi University College of Health Sciences, Eldoret, Kenya ${ }^{4}$ Department of Medicine, Duke University, Durham, North Carolina, USA

${ }^{5}$ Department of Medicine, Icahn School of Medicine at Mount Sinai, New York City, New York, USA

${ }^{6}$ Academic Model Providing Access to Healthcare (AMPATH), Eldoret, Kenya ${ }^{7}$ Department of Sociology, Psychology and Anthropology, School of Arts and Social Sciences, Moi University, Eldoret, Kenya

${ }^{8}$ Department of Pharmacy Practice, Purdue University, West Lafayette, Indiana, USA ${ }^{9}$ Department of Preventive Medicine, University of Southern California, Los Angeles, California, USA

${ }^{10}$ Department of Population Health, NYU Grossman School of Medicine, New York City, New York, USA

Twitter Rajesh Vedanthan @rvedanthan 
Acknowledgements The authors wish to thank Darinka Gadikota-Klumpers, and Renee Bischoff for their invaluable support. We also express our gratitude to the BIGPIC participants, research staff and local leaders who have made the study possible. We wish to thank Aileen Li for assistance with the Figures.

Contributors SGR, AKD, TWV, SAC, JWH and RV conceptualised the study and designed the study. PK, WM, RM and VO acquired and maintained the data. SGR, AKD, JHK, GSB, SAC, VF, CRH, VN, SDP, TWV, JWH and RV analysed and interpreted the data. SGR, AKD and RV wrote the manuscript. SGR, AKD, SAC, TWV, JWH and $\mathrm{RV}$ critically revised the manuscript for important intellectual content. All authors approved the final manuscript.

Funding The BIGPIC trial is supported by the National Heart, Lung, and Blood Institute of the National Institutes of Health under award number 5R01HL125487. The content is solely the responsibility of the authors and does not necessarily represent the official views of the National Institutes of Health. Samuel Ruchman was supported by the American Heart Association 2017 Student Scholarship in Cardiovascular Disease.

Competing interests None declared.

Patient consent for publication Not required

Ethics approval The BIGPIC trial is approved by the Institutional Review Boards at the Icahn School of Medicine at Mount Sinai and the NYU Grossman School of Medicine, both in New York, NY, and by the Institutional Research and Ethics Committee at Moi University, Eldoret, Kenya.

Provenance and peer review Not commissioned; externally peer reviewed.

Data availability statement Data are available upon reasonable request. Data will be made available upon reasonable request to the corresponding author and approval by the AMPATH Research Program.

Supplemental material This content has been supplied by the author(s). It has not been vetted by BMJ Publishing Group Limited (BMJ) and may not have been peer-reviewed. Any opinions or recommendations discussed are solely those of the author(s) and are not endorsed by BMJ. BMJ disclaims all liability and responsibility arising from any reliance placed on the content. Where the content includes any translated material, BMJ does not warrant the accuracy and reliability of the translations (including but not limited to local regulations, clinical guidelines, terminology, drug names and drug dosages), and is not responsible for any error and/or omissions arising from translation and adaptation or otherwise.

Open access This is an open access article distributed in accordance with the Creative Commons Attribution Non Commercial (CC BY-NC 4.0) license, which permits others to distribute, remix, adapt, build upon this work non-commercially, and license their derivative works on different terms, provided the original work is properly cited, appropriate credit is given, any changes made indicated, and the use is non-commercial. See: http://creativecommons.org/licenses/by-nc/4.0/.

\section{ORCID iDs}

Samuel G Ruchman http://orcid.org/0000-0002-1950-0924

Allison K Delong http://orcid.org/0000-0001-8660-8073

Rajesh Vedanthan http://orcid.org/0000-0001-7138-2382

\section{REFERENCES}

1 World Health Organization. Global status report on noncommunicable diseases 2014. Geneva, Switzerland: World Health Organization, 2014. https://www.who.int/nmh/publications/ncd-status-report-2014/ en/

2 Benziger CP, Roth GA, Moran AE. The global burden of disease study and the preventable burden of ncd. Glob Heart 2016;11:393-7.

3 Christakis NA, Fowler JH. The spread of obesity in a large social network over 32 years. N Engl J Med 2007;357:370-9.

4 Pachucki MA, Jacques PF, Christakis NA. Social network concordance in food choice among spouses, friends, and siblings. Am J Public Health 2011:101:2170-7.

5 Christakis NA, Fowler JH. The collective dynamics of smoking in a large social network. N Engl J Med 2008;358:2249-58.

6 Alexander C, Piazza M, Mekos D, et al. Peers, schools, and adolescent cigarette smoking. J Adolesc Health 2001;29:22-30.

7 Valente TW, Fujimoto K, Chou C-P, et al. Adolescent affiliations and adiposity: a social network analysis of friendships and obesity. $J$ Adolesc Health 2009;45:202-4.

8 Valente TW. Social networks and health: models, methods, and applications. New York; Oxford: Oxford University Press, 2010.
9 Robalino JD, Macy M. Peer effects on adolescent smoking: are popular teens more influential? PLoS One 2018;13:e0189360.

10 Campbell R, Starkey F, Holliday J, et al. An informal school-based peer-led intervention for smoking prevention in adolescence (assist): a cluster randomised trial. Lancet 2008;371:1595-602.

11 Moore S, Salsberg J, Leroux J. Advancing social capital interventions from a network and population health perspective. In: Kawachi I, Takao S, Subramanian SV, eds. Global perspectives on social capital and health. New York, NY: Springer, 2013: 189-203.

12 Centola D. An experimental study of homophily in the adoption of health behavior. Science 2011;334:1269-72.

13 Small ML. Weak ties and the core discussion network: why people regularly discuss important matters with unimportant alters. Soc Networks 2013;35:470-83.

14 Hurlbert JS, Haines VA, Beggs JJ. Core networks and tie activation: what kinds of routine networks allocate resources in nonroutine situations? Am Sociol Rev 2000;65:598-618.

15 Perry BL, Pescosolido BA, Borgatti SP. Egocentric network analysis: foundations, methods, and models. Cambridge, England: Cambridge University Press, 2018.

16 O'Malley AJ, Arbesman S, Steiger DM, et al. Egocentric social network structure, health, and pro-social behaviors in a national panel study of Americans. PLoS One 2012;7:e36250.

17 Marquez B, Norman G, Fowler J, et al. Egocentric networks and physical activity outcomes in Latinas. PLoS One 2018;13:e0199139.

18 Oladele CR, Thompson T-A, Wang K, et al. Egocentric health networks and cardiovascular risk factors in the ECHORN cohort study. J Gen Intern Med 2020;35:784-791.

19 Nagayoshi M, Everson-Rose SA, Iso H, et al. Social network, social support, and risk of incident stroke: atherosclerosis risk in Communities study. Stroke 2014;45:2868-73.

20 Alvergne A, Gurmu E, Gibson MA, et al. Social transmission and the spread of modern contraception in rural Ethiopia. PLoS One 2011;6:e22515.

21 Sandberg J. Infant mortality, social networks, and subsequent fertility. Am Sociol Rev 2006;71:288-309.

22 Mertens F, Saint-Charles J, Lucotte M, et al. Emergence and robustness of a community discussion network on mercury contamination and health in the Brazilian Amazon. Health Educ Behav 2008;35:509-21.

23 Zelner JL, Trostle J, Goldstick JE, et al. Social connectedness and disease transmission: social organization, cohesion, village context, and infection risk in rural Ecuador. Am J Public Health 2012;102:2233-9.

24 Perkins JM, Subramanian SV, Christakis NA. Social networks and health: a systematic review of sociocentric network studies in lowand middle-income countries. Soc Sci Med 2015;125:60-78.

25 Kim DA, Hwong AR, Stafford D, et al. Social network targeting to maximise population behaviour change: a cluster randomised controlled trial. Lancet 2015;386:145-53.

26 Perry BL, Pescosolido BA. Functional specificity in discussion networks: the influence of general and problem-specific networks on health outcomes. Soc Networks 2010;32:345-57.

27 Perry BL, Pescosolido BA. Social network activation: the role of health discussion partners in recovery from mental illness. Soc Sci Med 2015;125:116-28.

28 Gray LJ, Taub NA, Khunti K, et al. The Leicester risk assessment score for detecting undiagnosed type 2 diabetes and impaired glucose regulation for use in a multiethnic UK setting. 2010:27:887-95.

29 Vedanthan R, Kamano JH, Chrysanthopoulou SA, et al. Group medical visit and microfinance intervention for patients with diabetes or hypertension in Kenya. J Am Coll Cardiol 2021;77:2007-18.

30 Vedanthan $\mathrm{R}$, Kamano $\mathrm{JH}$, Lee $\mathrm{H}$, et al. Bridging income generation with group integrated care for cardiovascular risk reduction: rationale and design of the BIGPIC study. Am Heart J 2017;188:175-85.

31 Marsden PV. Core discussion networks of Americans. Am Sociol Rev 1987:52:122-31.

32 Moore AR. Older people living with HIV/AIDS (OPLWHA) in Lomẻ, Togo: personal networks and disclosure of serostatus. Ageing Int 2013;38:218-32.

33 Bates SJ, Trostle J, Cevallos WT, et al. Relating diarrheal disease to social networks and the geographic configuration of communities in rural Ecuador. Am J Epidemiol 2007;166:1088-95.

34 Trostle JA, Hubbard A, Scott J, et al. Raising the level of analysis of food-borne outbreaks: food-sharing networks in rural coastal Ecuador. Epidemiology 2008;19:384.

35 Miguel E, Kremer M. Networks, social learning, and technology adoption: the case of deworming drugs in Kenya. Working paper No. 61. center for labor economics, University of California, Berkeley, 2003. Available: http://cle.berkeley.edu/wp/wp61.pdf 
36 Mertens F, Saint-Charles J, Mergler D. Social communication network analysis of the role of participatory research in the adoption of new fish consumption behaviors. Soc Sci Med 2012;75:643-50.

37 National Cholesterol Education Program (NCEP) Expert Panel on Detection, Evaluation, and Treatment of High Blood Cholesterol in Adults (Adult Treatment Panel III). Third report of the National cholesterol education program (NCEP) expert panel on detection, evaluation, and treatment of high blood cholesterol in adults (adult treatment panel III) final report. Circulation 2002;106:3143-421.

38 World Health Organization. The who stepwise approach to noncommunicable disease risk factor surveillance (steps. Geneva, Switzerland, 2020. https://www.who.int/ncds/surveillance/steps/ instrument/en/

39 Hippisley-Cox J, Coupland C, Brindle P. Development and validation of QRISK3 risk prediction algorithms to estimate future risk of cardiovascular disease: prospective cohort study. BMJ 2017;357:j2099.

40 Smits J, Steendijk R. The International wealth index (IVI). Soc Indic Res 2015;122:65-85

41 Keates AK, Mocumbi AO, Ntsekhe M, et al. Cardiovascular disease in Africa: epidemiological profile and challenges. Nat Rev Cardiol 2017;14:273-293.

42 Gómez-Olivé FX, Ali SA, Made F, et al. Regional and sex differences in the prevalence and awareness of hypertension: an H3Africa AWI-Gen study across 6 sites in sub-Saharan Africa. Glob Heart 2017;12:81-90.

43 Mkuu RS, Gilreath TD, Wekullo C, et al. Social determinants of hypertension and type-2 diabetes in Kenya: a latent class analysis of a nationally representative sample. PLoS One 2019;14:e0221257.

44 McKenzie BL, Santos JA, Geldsetzer P, et al. Evaluation of sex differences in dietary behaviours and their relationship with cardiovascular risk factors: a cross-sectional study of nationally representative surveys in seven low- and middle-income countries. Nutr J 2020:19:3

45 Okube OT, Kimani ST, Mirie W. Gender differences in the pattern of socio-demographics relevant to metabolic syndrome among Kenyan adults with central obesity at a mission hospital in Nairobi, Kenya. High Blood Press Cardiovasc Prev 2020;27:61-82.

46 National Clinical Guideline Centre (UK). Lipid modification: cardiovascular risk assessment and the modification of blood lipids for the primary and secondary prevention of cardiovascular disease (NICE clinical guidelines, no. 181). London, England: National Institute for Health and Care Excellence (UK), 2014. https://www. ncbi.nlm.nih.gov/books/NBK248067/

47 Chobanian AV, Bakris GL, Black HR, et al. Seventh report of the joint National Committee on prevention, detection, evaluation, and treatment of high blood pressure. Hypertension 2003;42:1206-52.

48 Leigh-Hunt N, Bagguley D, Bash K, et al. An overview of systematic reviews on the public health consequences of social isolation and Ioneliness. Public Health 2017:152:157-71.

49 Valtorta NK, Kanaan M, Gilbody S, et al. Loneliness and social isolation as risk factors for coronary heart disease and stroke: systematic review and meta-analysis of longitudinal observational studies. Heart 2016;102:1009-16.

50 Rabin R, de Charro F. EQ-5D: a measure of health status from the EuroQol group. Ann Med 2001;33:337-43.

51 Janssen MF, Lubetkin El, Sekhobo JP, et al. The use of the EQ$5 \mathrm{D}$ preference-based health status measure in adults with type 2 diabetes mellitus. Diabet Med 2011;28:395-413.

52 Grandy S, Fox KM. EQ-5D visual analog scale and utility index values in individuals with diabetes and at risk for diabetes: findings from the study to help improve early evaluation and management of risk factors leading to diabetes (shield). Health Qual Life Outcomes 2008;6:18.

53 Dyer MTD, Goldsmith KA, Sharples LS, et al. A review of health utilities using the EQ-5D in studies of cardiovascular disease. Health Qual Life Outcomes 2010;8:13.

54 Yan R, Gu H-Q, Wang W, et al. Health-Related quality of life in blood pressure control and blood lipid-lowering therapies: results from the chief randomized controlled trial. Hypertens Res 2019;42:1561-71.

55 Efron B. Large-Scale simultaneous hypothesis testing. J Am Stat Assoc 2004;99:96-104.

56 Kimando MW, Otieno FCF, Ogola EN, et al. Adequacy of control of cardiovascular risk factors in ambulatory patients with type 2 diabetes attending diabetes out-patients clinic at a County Hospital, Kenya. BMC Endocr Disord 2017;17:73.
57 GBD 2017 Diet Collaborators. Health effects of dietary risks in 195 countries, 1990-2017: a systematic analysis for the global burden of disease study 2017. Lancet 2019;393:1958-72.

58 Ministry of Health (Kenya). Kenya stepwise survey for non communicable diseases risk factors: 2015 report. Nairobi, Kenya, 2015. Available: https://www.who.int/ncds/surveillance/steps/Kenya 2015 STEPS_Report.pdf

59 Ngaruiya C, Abubakar H, Kiptui D, et al. Tobacco use and its determinants in the 2015 Kenya who steps survey. BMC Public Health 2018:18:1223.

60 Vogt TM, Mullooly JP, Ernst D, et al. Social networks as predictors of ischemic heart disease, cancer, stroke and hypertension: incidence, survival and mortality. J Clin Epidemiol 1992;45:659-66.

61 Kawachi I, Colditz GA, Ascherio A, et al. A prospective study of social networks in relation to total mortality and cardiovascular disease in men in the USA. J Epidemiol Community Health 1996;50:245-51.

62 Eng PM, Rimm EB, Fitzmaurice G, et al. Social ties and change in social ties in relation to subsequent total and cause-specific mortality and coronary heart disease incidence in men. Am J Epidemiol 2002;155:700-9.

63 Shah S, Cook DG. Inequalities in the treatment and control of hypertension: age, social isolation and lifestyle are more important than economic circumstances. J Hypertens 2001;19:1333-40.

64 Redondo-Sendino A, Guallar-Castillón P, Banegas JR, et al. [Relationship between social network and hypertension in older people in Spain]. Rev Esp Cardiol 2005;58:1294-301.

65 Shelton RC, McNeill LH, Puleo E, et al. The association between social factors and physical activity among low-income adults living in public housing. Am J Public Health 2011;101:2102-10.

66 Marquez B, Elder JP, Arredondo EM, et al. Social network characteristics associated with health promoting behaviors among Latinos. Health Psychol 2014;33:544-53.

67 Willey JZ, Paik MC, Sacco R, et al. Social determinants of physical inactivity in the Northern Manhattan study (NOMAS). J Community Health 2010;35:602-8.

68 Mötteli S, Dohle S. Egocentric social network correlates of physical activity. J Sport Health Sci 2020;9:339-344.

69 Wellman B, Wortley S. Different strokes from different folks: community ties and social support. Am J Sociol 1990;96:558-88.

70 Kowalski K, Rhodes R, Naylor P-J, et al. Direct and indirect measurement of physical activity in older adults: a systematic review of the literature. Int J Behav Nutr Phys Act 2012;9:148.

71 Park PH, Chege P, Hagedorn IC, et al. Assessing the accuracy of a point-of-care analyzer for hyperlipidaemia in Western Kenya. Trop Med Int Health 2016;21:437-44.

72 Livingstone S, Morales DR, Donnan PT, et al. Effect of competing mortality risks on predictive performance of the QRISK3 cardiovascular risk prediction tool in older people and those with comorbidity: external validation population cohort study. Lancet Healthy Longev 2021;2:e352-61.

73 Ekun OA, Fasela EO, Oladele DA, et al. Risks of cardio-vascular diseases among highly active antiretroviral therapy (HAART) treated HIV seropositive volunteers at a treatment centre in Lagos, Nigeria. Pan Afr Med J 2021;38:206.

74 Rajman I, Knapp L, Morgan T, et al. African genetic diversity: implications for cytochrome P450-mediated drug metabolism and drug development. EBioMedicine 2017;17:67-74.

75 Choudhury A, Aron S, Sengupta D, et al. African genetic diversity provides novel insights into evolutionary history and local adaptations. Hum Mol Genet 2018;27:R209-18.

76 Mills KT, Stefanescu A, He J. The global epidemiology of hypertension. Nat Rev Nephrol 2020;16:223-7.

77 Boateng D, Wekesah F, Browne JL, et al. Knowledge and awareness of and perception towards cardiovascular disease risk in sub-Saharan Africa: a systematic review. PLoS One 2017;12:e0189264.

78 Walli-Attaei M, Joseph P, Rosengren A, et al. Variations between women and men in risk factors, treatments, cardiovascular disease incidence, and death in 27 high-income, middle-income, and low-income countries (pure): a prospective cohort study. Lancet 2020;396:97-109.

79 Valente TW. Social network thresholds in the diffusion of innovations. Soc Networks 1996;18:69-89.

80 Valente TW. Network interventions. Science 2012;337:49-53. 